\title{
SISTEMATIZAÇÃO DAASSISTÊNCIA DE ENFERMAGEM NA PREVENÇÃO DA LESÃO TECIDUAL POR PRESSÃO
}

Michele Mendes Rodrigues ${ }^{1}$, Michele de Souza e Souza², Jorge Lima Silva ${ }^{3}$

\begin{abstract}
RESUMO: A lesão tecidual por pressão (LTP) é uma complicação bastante comum, torna-se um problema para os clientes e um desafio para os enfermeiros. Estudos mostram que a sistematização da assistência de enfermagem na prevenção de LTP constitui um meio para o enfermeiro promover a saúde e manter o bem-estar durante a recuperação do cliente. Nesse contexto, foi delimitado como objeto de estudo a sistematização da assistência de enfermagem na prevenção de LTP. O objetivo dessa pesquisa foi sistematizar a assistência de enfermagem tendo em vista a prevenção de LTP. Pesquisa de natureza descritiva realizada através de revisão bibliográfica analítica e baseada em obras secundárias. Foi realizada préleitura do material e análise inicial em seguida leitura interpretativa. Percebeu-se que o profissional de enfermagem pode sistematizar o cuidado por meio conhecimentos técnico-científicos abrangentes.
\end{abstract}

PALAVRAS-CHAVE: Úlcera de pressão; Prevenção e controle; Assistência de enfermagem.

\section{SYSTEMATIZATION OF NURSING CARE TO PREVENT PRESSURE-RELATED TISSUE INJURY}

ABSTRACT: Pressure-related tissue injury (PTI) is a common complication, becoming a problem for patients and a challenge for nurses. Studies show that the systematization of nursing care to prevent PTI is a way for nurses to promote health and keep clients' welfare during their recovery; in this context, it was defined as study object the systematization of nursing care in the prevention of PTI. The objective of this research study was the systematization of nursing care in the prevention of PTI. Descriptive study, held as a literature review based on secondary works. A previous reading and initial analysis of the material were carried out, followed by interpretative reading. It was perceived that nursing professionals can systemize care by means of broad technical-scientific knowledge.

KEYWORDS: Pressure ulcer; Prevention and control; Nursing care.

\section{SISTEMATIZACION DEL CUIDADO DE ENFERMERÍA EN PREVENCIÓN DE DAÑO TISULAR POR PRESIÓN}

RESUMEN: La lesión tecidual por presión (LTP) es una complicación bastante común y se hace un problema para los pacientes y un desafío para los enfermeros. Estudios muestran que la sistematización de la asistencia de enfermería en la prevención de LTP constituye un medio para el enfermero promover la salud y mantener el bienestar durante la recuperación del paciente. En ese contexto, fue delimitado como objeto de estudio la sistematización de la asistencia de enfermería en la prevención de LTP. El objetivo de esa investigación fue sistematizar la asistencia de enfermería con miras a la prevención de LTP. Estudio descriptivo y exploratório, hecho por medio de revisión de la literatura basada en obras secundarias. Fue realizada prelectura del material y análisis inicial seguida de lectura interpretativa. Se percibió que el profesional de enfermería puede sistematizar el cuidado por medio de conocimientos técnico-científicos amplios.

PALABRAS CLAVE: Úlcera por presión; Prevención y control; Cuidados de enfermería.

${ }^{1}$ Acadêmica do Curso de Graduação em Enfermagem. Centro Universitário Plínio Leite-UNIPLI.

${ }^{2}$ Acadêmica do Curso de Graduação em Enfermagem. UNIPLI.

${ }^{3}$ Professor colaborador do Curso de Pós-graduação em Enfermagem em Promoção da Saúde. Universidade Federal Fluminense-UFF. Professor orientador-UNIPLI.

Autor correspondente:

Jorge Luiz Lima da Silva

Rua Dr. Celestino, 74 - 24020-091 - Niterói-RJ

Recebido: 16/04/08

E-mail: jorgeluizlima@vm.uff.br

Aprovado: 28/10/08

Cogitare Enferm 2008 Out/Dez; 13(4):566-75 


\section{INTRODUÇÃO}

A decisão de elaborar este trabalho ocorreu durante os estágios em clínica médica do curso do curso de graduação em enfermagem, em que foi percebida a realidade dos clientes restritos ao leito por longo período de tempo. Sabe-se que a maioria destes clientes desenvolverão, lesão tecidual por pressão (LTP) ${ }^{(1)}$. Naquele momento, foi percebido que alguns enfermeiros apresentavam necessidade de atualização sobre LTP, ou tinham dificuldade em aplicar seus conhecimentos de forma sistematizada.

Atualmente, é notório que a maioria das LTP podem ser evitadas ${ }^{(2)}$. Em vários países, pesquisas mostram que, preveni-las custa menos do que tratálas. O custo da internação de um cliente portador de LTP nos E.U.A. é de U\$ 37.000, contra U\$ 14.000 para a mesma internação em que a prevenção mostrase eficaz ${ }^{(3)}$.

No Brasil, estudos demonstram a incidência de LTP em alguns hospitais( ${ }^{(4-5)}$, porém não há uma estimativa de casos em todo o país. Em 1989, a National Pressure Ulcer Advisory Panel (NPUAP), órgão responsável pelas diretrizes para a prevenção e tratamento de LTP nos E.U.A.(6), estimou que mais de 1 milhão de clientes desenvolveram LTP naquele ano ${ }^{(7)}$, o que gerou um custo entre 1,3 a 1,5 bilhões de dólares ${ }^{(2)}$. Em 1994, nos E.U.A., aproximadamente 2,1 milhões de clientes desenvolveram LTP. O custo para o sistema de saúde foi de 4 a 7 mil dólares/mês por cliente ${ }^{(8)}$. Desta forma, observa-se que a LTP é uma complicação bastante comum, representa um problema para os clientes e um desafio para os enfermeiros que prestam assistência através de cuidados diários ${ }^{(9)}$.

Quando o cliente desenvolve LTP, a equipe de enfermagem questiona a qualidade da assistência, sentese frustrada e imputa ao enfermeiro uma significativa parte da responsabilidade ${ }^{(10)}$. O custo do tratamento do cliente se eleva, seu estado geral de saúde piora e, como consequência, pode evoluir para um mal prognóstico ${ }^{(1)}$.

As LTP estão entre as complicações que mais acometem clientes hospitalizados, aumentam o tempo de internação e de recuperação, e ainda expõe o cliente ao risco de desenvolvimento de complicações como infecção. O cliente tem sua independência e funcionalidade reduzidas e sua autoestima prejudicada $^{(9,11-12)}$. Porém, o fator mais nocivo que tem se observado no aparecimento de LTP é o sofrimento físico e emocional, uma vez que ela envolve dor e alterações graves na pele.
Correspondendo a $16 \%$ do peso corporal, a pele é o maior órgão do corpo humano e tem como principais funções: defesa orgânica, regulação térmica, revestir, proteger contra diversos agentes do meio ambiente e funções sensoriais. Constitui-se de três camadas: epiderme, derme e hipoderme ${ }^{(13)}$. A epiderme é a mais fina e mais externa das camadas. A derme, camada da pele composta por fibras, vasos sangüíneos e terminações nervosas, fornece suporte, resistência, sangue e oxigênio à pele. A hipoderme, conhecida como tecido subcutâneo, é a camada mais profunda da pele, formada basicamente por células de gordura, funciona como um depósito de calorias e mantém a temperatura corporal $^{(14)}$.

A LTP tem como definição área de necrose tissular que se forma quando o tecido é comprimido entre uma proeminência óssea e uma superfície dura, por um período de tempo ${ }^{(15-16)}$.

Muitas instituições carecem da aplicação de sistematização da assistência como terapêutica de prevenção de LTP, conseqüentemente, a assistência prestada aos clientes em risco de desenvolverem LTP é feita de acordo com os conhecimentos de cada enfermeiro em particular. Esta situação resulta em intervenções aleatórias e descontínuas acabam por contribuir para a menor probabilidade de que essas medidas preventivas tenham eficácia ${ }^{(4,17)}$. Estudos demonstraram que a utilização de protocolos sistematizados, desenvolvidos através de pesquisas, são eficazes para prevenção de LTP, fato evidenciado pela redução da incidência ${ }^{(9,18)}$.

Acredita-se que o enfermeiro deve estar em constante processo de atualização, para apropriar-se de conhecimentos relacionados à assistência de enfermagem, adequar-se às suas finalidades essenciais e se motivar na busca da melhoria da qualidade ${ }^{(9)}$. A prevenção necessita de uma estratégia individual precisa, o que exige muita dedicação e preparo do profissional, para uma intervenção de enfermagem ajustada e eficaz ${ }^{(19)}$.

Mediante ao exposto, o objeto do estudo deste trabalho foi a sistematização da assistência de enfermagem com vista à prevenção de LTP. A pesquisa teve como objetivo: descrever a sistematização da assistência de enfermagem na prevenção de LTP.

\section{CAMINHO PERCORRIDO}

A pesquisa de natureza descritiva, realizada através de revisão bibliográfica analítica, aborda o tema 
em questão publicadas no período de junho de 1987 a julho de 2008.

A coleta do material para a pesquisa foi realizada no período de agosto a setembro de 2008. O levantamento foi realizado em ambiente virtual na Biblioteca Virtual de Saúde (BVS), em que dissertações e artigos foram incluídos, nos resultados de busca com os seguintes descritores: "úlcera por pressão", "prevenção e assistência de enfermagem”, "sistematização da assistência e úlcera". Estes termos foram utilizados de forma conjunta e isolados. O descritor "plano de assistência" apresentou poucas obras referentes ao objeto de estudo, mesmo quando somado ao termo "úlcera por pressão". As obras idênticas repedidas em bases de dados diferentes foram eliminadas, considerou-se seu primeiro registro. Além do material encontrado na BVS foi utilizado na pesquisa livros e periódicos da área de saúde, os quais funcionaram como alicerce conceitual.

Primeiramente as obras foram armazenadas em computador, para que em seguida fosse realizada uma pré-seleção de acordo com a leitura dos resumos. Nesta fase, buscou-se a relação entre o conteúdo, título, resumo, e se atendiam ao objeto do presente estudo. Na fase de seleção, as obras foram lidas na íntegra com atenção especial para os resultados e conclusão das obras, os trabalhos que não apresentavam qualquer relação com o caráter preventivo foram excluídos.

Realizada a triagem das obras foram obtidos 25 artigos, 6 dissertações, 14 livros para embasamento teórico, 3 arquivos de outras categorias (2 Guidelines e 1 manual).

Na fase de interpretação, as obras foram lidas e analisadas sendo que os eixos temáticos dos resultados foram organizados, de acordo com as fases da metodologia da assistência de enfermagem, para que fossem discutidos. Após a construção das fases da sistematização, percebeu-se que somente os estudos encontrados em meio virtual não subsidiaram o aspecto conceitual básico, visto que abordavam o tratamento de prevenção secundária. Deste ponto em diante os autores buscaram livros na biblioteca física de duas universidades. Foram selecionadas as obras mais recentes e que mostrassem relação com o caráter preventivo.

Depois das etapas descritas acima, foram construídos nos resultados itens que abordam as principais causas e características das LTP, os princípios para sistematizar e as fases do processo do cuidado.

\section{RESULTADOS}

\section{Lesão tecidual por pressão: causas e classificação}

LTP é definida como uma área localizada de necrose tissular que se desenvolve quando a pele é comprimida entre o osso e uma superfície dura ${ }^{(6)}$. Uma segunda definição, mais ampla, considera LTP qualquer ferida causada por pressão prolongada que resulta em lesão nos tecidos adjacentes ${ }^{(20)}$. Outro conceito seria: lesões provenientes de hipóxia tissular, levando à necrose tecidual que ocorrem quando a pressão que é aplicada na pele é maior que a pressão capilar normal (32 mm Hg/arteríolas e 12 mm Hg / vênulas), em um período de tempo ${ }^{(21)}$.

Atualmente, as LTP são classificadas por estágios, de I a IV, pela profundidade de comprometimento da pele e outros tecidos. O sistema de estagiamento é utilizado desde 1989 e foi desenvolvido pela NPUAP (National Pressure Ulcer Advisory Panel): Estágio I: eritema que não desaparece em 24 horas, após a pressão ser aliviada; Estágio II: lesão dérmica, como, flictemas, fissuras e abrasões; Estágio III: lesão cutânea com exposição do subcutâneo com margens definidas, não chegando até a fáscia muscular; Estágio IV: exposição muscular e/ou óssea ${ }^{(21-22)}$.

Deve-se atentar para o fato de que toda lesão que atinge determinado estágio encontra-se em estágio de cicatrização, mesmo que apresente a formação de um novo tecido permanece no grau em que foi classificada, embora seja caracterizada como: em cicatrização $0^{(23)}$.

\section{Princípios para sistematizar a assistência de enfermagem na prevenção de LTP}

Prevenção pode ser definida como uma estratégia orientada para o futuro, em que o resultado será a melhoria da qualidade, direcionando análises e ações para a correção dos processos de produção de cuidado ${ }^{(24)}$. As ações de prevenção visam impedir que o estímulo desencadeante agrida o indivíduo causando doença ${ }^{(25)}$. O valor da prevenção, como meio de atenuar as morbidades e reduzir a mortalidade, é indiscutível.

Estudos demonstram que a prevenção de LTP não é uma prioridade para a enfermagem. Porém, como a afecção se apresenta como problema para o cliente, seus familiares e para a instituição de saúde, o enfermeiro deve conscientizar-se da importância de 
atuar em medidas profiláticas. Para que este cuidado seja eficaz, o profissional deve conhecer os mecanismos da LTP bem como a realidade de instituição na qual trabalha ${ }^{(15)}$.

A prevenção do desenvolvimento de LTP é uma atividade essencialmente do profissional de nível superior, sendo o mais capacitado para lidar com esse problema ${ }^{(26)}$. Ao elaborar um plano de assistência ao cliente, visando reduzir ao mínimo os riscos para desenvolvimento de lesões, o enfermeiro deve lembrar que o cliente é um todo constituído de corpo, mente e espírito, e que sofre influência do meio ambiente, exigindo uma assistência integral ${ }^{(9)}$. Para tanto, destacase a importância de tocar o corpo do cliente para a manutenção de um estado físico-emocional saudável, na tentativa de evitar danos corporais ${ }^{(26)}$. Situação oportuna para estabelecer um vínculo de confiança com o cliente se dá durante o exame físico, quando toca-se o corpo do cliente a procura de alterações na pele.

Sistematizar é construir a memória de uma experiência, divulgar conhecimentos relacionados à prática e estimular a confrontação de idéias. Podemos organizar conjuntos de experiências, elaborando assim um projeto representativo da intervenção. Para implementar a metodologia é importante refletir antes de iniciar o processo ${ }^{(27)}$. Através da sistematização de enfermagem, é possível proporcionar ao cliente uma assistência organizada, pautada em conhecimentos científicos, aumentando as chances de sucesso da intervenção de enfermagem ${ }^{(28)}$.

A aplicação da metodologia da assistência de enfermagem é o elemento utilizado pelo enfermeiro para pôr em prática seus conhecimentos técnicocientíficos em benefício do cliente, caracterizando sua prática profissional e definindo assim o seu papel ${ }^{(29)}$. Esse processo não é passivo, pelo contrário, os enfermeiros envolvidos no processo assistencial individualizado devem estar constantemente refletindo sobre suas ações de forma dinâmica e participativa ${ }^{(30)}$.

$\mathrm{Na}$ assistência de enfermagem visando à prevenção de lesões teciduais por pressão, a sistematização se dá através das etapas: histórico de enfermagem, diagnóstico de enfermagem, planos de cuidados de enfermagem e evolução de enfermagem.

É através do histórico de enfermagem que se são obtidas as informações necessárias sobre o estado geral de saúde do cliente, sobre a integridade da pele e grau de risco de desenvolvimento de LTP a que o cliente está exposto. É importante que todas as informações necessárias sejam coletadas no momento da admissão do cliente na unidade ${ }^{(31)}$. O enfermeiro deve apurar informações como: idade, doenças de base, situação nutricional, anemia, uso de medicamentos, história prévia de perda da integridade cutânea, presença de edemas e/ou infecção, flictema em região de proeminência óssea, turgor de pele, sensibilidade e motricidade, incontinência urinária e fecal.

É importante que o enfermeiro faça uma avaliação abrangente sobre o cliente, coletando as informações necessárias, pois é com esses dados que irá estabelecer os diagnósticos de enfermagem, como por exemplo ${ }^{(31-32)}$.

As causas do desenvolvimento de LTP são variadas, envolvem questões externas, do ambiente e interna, do organismo. É uma afecção que se desenvolve a partir de distúrbios individuais de cada cliente e de características dos cuidados que lhe são oferecidos, estes fatores somados, ocasionam o aparecimento de $\operatorname{LTP}^{(31)}$.

Os fatores externos estão ligados ao mecanismo da lesão, pois impedem uma circulação eficiente para nutrição e oxigenação da pele e refletem o grau em que a pele é exposta. São eles: pressão, cisalhamento, friç̧ão ${ }^{(33)}$.

A pressão física é considerada o fator mais importante no desenvolvimento de LPT, ocorre quando o tecido mole é comprimido entre uma saliência óssea e superfície dura, o que impede o fluxo eficiente de sangue, causando isquemia e podendo até levar a morte dos tecidos (necrose) devido a hipóxia ${ }^{(34)}$. O cisalhamento acontece quando o cliente permanece imóvel na cama, enquanto as camadas da pele movimentam-se. Se duas superfícies são esfregadas uma contra outra, como por exemplo: no arrastar o cliente ao invés de levantá-lo, as camadas superiores das células epiteliais são removidas, isto é chamado de fricção. A umidade que é freqüente quando o cliente sofre de incontinência urinária, fecal ou apresenta suor excessivo, pode aumentar o efeito da fricção $0^{(1-10)}$.

Os fatores internos dizem respeito ao estado de saúde do cliente influenciando na constituição e integridade de sua pele ${ }^{(10)}$. Pessoas acometidas por doenças agudas são mais vulneráveis a LTP, tendo como fatores precipitantes: dor, pressão sanguínea baixa, insuficiência cardíaca, insuficiência vasomotora, vasoconstricção periférica devido ao choque e outros $^{(33)}$. Clientes com quadros graves e instáveis, com risco de falência de sistemas, também estão entre os mais suscetíveis a $\operatorname{LTP}^{(9)}$. A perfusão tissular diminuída também aumenta o risco de LTP, isto pode 
acontecer com clientes que sofrem de diabetes melito, obesidade e edema ${ }^{(1)}$.

Clientes com baixos níveis de hemoglobina também estão em risco de desenvolver lesão tecidual, ocasionada pela diminuição da capacidade do sangue em transportar oxigênio e atender as demandas metabólicas do organismo ${ }^{(35)}$. Consideram-se ainda como fatores internos: condições nutricionais; idade avançada; incontinência urinária e fecal; mobilidade reduzida ou ausente; peso corpóreo; distúrbios vasculares; distúrbios neurológicos e infecções ${ }^{(33,36)}$.

As deficiências nutricionais, como desidratação, anemia e emagrecimento, diminuem a elasticidade da pele, reduzem o oxigênio dos tecidos e dificultam a cicatrização. Nutrientes como vitamina C, por exemplo, são necessários para a manutenção e reparação tissulares $^{(1)}$.

Quando a percepção sensorial está danificada ou ausente, o cliente tem a sensibilidade à dor e ao desconforto alterados, impedindo que sejam identificadas regiões do corpo que precisam de alívio de pressão. Com a mobilidade reduzida, o cliente reduz a freqüência de mudança de posição impossibilitado de aliviar a pressão sozinhoo ${ }^{(33)}$. O contato prolongado com a umidade produz maceração da pele, que reage às substâncias cáusticas das excreções e fica irritada, tornando-se mais vulnerável à ruptura por pressão e, que em caso de rompimento, a lesão acaba invadida por microorganismos, ocorrendo infecção ${ }^{(1)}$.

Em idosos, a espessura epidérmica e a perfusão tissular diminuem. A pele fica mais seca por causa da atividade diminuída das glândulas sebáceas e sudoríparas. Os músculos atrofiam e as estruturas ósseas ficam salientes. A percepção sensorial diminuída e a dificuldade de se reposicionar contribuem para pressão prolongada sobre uma mesma área corporal $^{(33)}$. Estas alterações decorrentes da idade tornam o idoso mais suscetível às $\mathrm{LTP}^{(1)}$, fato evidenciado por estudos que apresentaram incidência de $10 \%$ a $20 \%$ em clientes desta faixa etária que estão acamados, e uma taxa de mortalidade de $70 \%$ ao ano. Cerca de 20\% desses idosos tem lesões teciduais de graus III e IV ${ }^{(35)}$.

\section{Diagnóstico de enfermagem}

Com o objetivo de padronizar os diagnósticos de enfermagem, a Associação Norte Americana dos Diagnósticos de Enfermagem (NANDA) criou um sistema de classificação de diagnósticos baseados nos problemas encontrados pelos enfermeiros em seus clientes. O julgamento clínico é ajustado às respostas do cliente, da família ou da comunidade aos problemas de saúde e processos vitais, reais ou potenciais ${ }^{(38)}$.

Com os dados obtidos, através do histórico, é possível estabelecer os diagnósticos de enfermagem para clientes em risco de desenvolver LTP. Esta fase da sistematização da assistência de enfermagem na prevenção de LTP é a base para a elaboração do plano de cuidados. Como diagnósticos de enfermagem observados nos clientes em risco de desenvolvimento de LTP, propõem-se os diagnósticos descritos no Quadro 1:

Quadro 1 - Diagnósticos de enfermagem para clientes em risco de desenvolvimento de LTP

\begin{tabular}{|c|c|}
\hline Diagnóstico & Definição \\
\hline $\begin{array}{l}\text { Senso-percepção } \\
\text { alterada }\end{array}$ & $\begin{array}{l}\text { Mudança na qualidade ou no tipo de estímulos percebidos, seguida de resposta diminuída, } \\
\text { exagerada, distorcida ou enfraquecida a tais estímulos. Define-se por desorientação no tempo, no } \\
\text { espaço ou com pessoas, mudança verificada ou relatada na acuidade sensorial, entre outros. Está } \\
\text { relacionado à recepção, transmissão e/ou integração sensorial alterada, entre outros }{ }^{(38-39)} \text {. }\end{array}$ \\
\hline $\begin{array}{l}\text { Integridade da pele } \\
\text { prejudicada }\end{array}$ & $\begin{array}{l}\text { Quando o cliente apresenta ou está em risco de apresentar dano ao tecido epitelial/dérmico. Este } \\
\text { diagnóstico é definido ao se observar, na avaliação e no histórico, informações como edema, } \\
\text { eritema, prurido e desnutrição. Ao utilizar este diagnóstico, o enfermeiro deve correlacioná-lo aos } \\
\text { efeitos da pressão, fricção, deslizamento e maceração }\end{array}$ \\
\hline $\begin{array}{l}\text { Mobilidade física } \\
\text { prejudicada }\end{array}$ & $\begin{array}{l}\text { Limitação dos movimentos físicos independentes. Define-se pela incapacidade de movimentação } \\
\text { significativa no ambiente físico ou leito, transferência e deambulação, entre outros. Relaciona-se com } \\
\text { dano perceptual ou cognitivo, enfraquecimento neuro-muscular e músculo-esquelético, entre } \\
\text { outros }^{(38-39) .}\end{array}$ \\
\hline $\begin{array}{l}\text { Mobilidade } \\
\text { prejudicada na } \\
\text { cama }\end{array}$ & $\begin{array}{l}\text { Quando o cliente apresenta ou está em risco de apresentar limitação de movimentos na cama, tendo } \\
\text { como características definidoras capacidade prejudicada para virar-se de um lado para o outro e } \\
\text { mudar de posição }{ }^{(38-39)} \text {. }\end{array}$ \\
\hline
\end{tabular}

Continua 
Continuação

\begin{tabular}{|c|c|}
\hline $\begin{array}{l}\text { Nutrição alterada: } \\
\text { menor que as } \\
\text { demandas } \\
\text { corporais }\end{array}$ & $\begin{array}{l}\text { Quando há ingestão de nutrientes que não atende as demandas metabólicas. Define-se por perda de } \\
\text { peso mesmo com ingestão alimentar adequada, peso corporal } 20 \% \text { ou mais abaixo do ideal, } \\
\text { fragilidade vascular; tônus muscular enfraquecido, diarréia entre outros. Relaciona-se com a } \\
\text { incapacidade de ingerir/digerir/absorver alimentos ou nutrientes, devido a fatores biológicos e } \\
\text { psicológicos }^{(38,39)} \text {. }\end{array}$ \\
\hline $\begin{array}{l}\text { Déficit no } \\
\text { autocuidado: } \\
\text { higiene corporal }\end{array}$ & $\begin{array}{l}\text { Habilidade prejudicada para realizar ou completar, por si mesmo, atividades de higiene corporal. } \\
\text { Tem como características definidoras: incapacidade para lavar o corpo ou parte deste. Relacionado } \\
\text { à força e resistência diminuídas, enfraquecimento músculo-esquelético, entre outros }{ }^{(38,39)} \text {. }\end{array}$ \\
\hline $\begin{array}{l}\text { de } \\
\text { de líquido }\end{array}$ & $\begin{array}{l}\text { Quando o cliente experimenta aumentada retenção de líquidos e edema. É definido por edema, } \\
\text { infiltração, anasarca, entre outros. Está relacionado com comprometimento dos mecanismos } \\
\text { reguladores, excessiva ingestão de líquidos e excessiva ingestão de sódio }{ }^{(38,39)} \text {. }\end{array}$ \\
\hline Dor & O cliente experimenta e relata a presença de severo desconforto ou sensação desconfortável ${ }^{(38,39)}$. \\
\hline $\begin{array}{l}\text { Incontinência } \\
\text { intestinal }\end{array}$ & Mudança nos hábitos intestinais caracterizada pela eliminação involuntária de fezes ${ }^{(38,39)}$. \\
\hline $\begin{array}{l}\text { Diarréia } \\
\text { por causa } \\
\text { desconhecida }\end{array}$ & $\begin{array}{l}\text { Mudança nos hábitos intestinais, caracterizada por freqüentes e inevitáveis eliminações de fezes } \\
\text { líquidas e não formadas. Define-se por dor abdominal, cólica, frequiência aumentada das } \\
\text { eliminações, entre outras }{ }^{(38,39)} \text {. }\end{array}$ \\
\hline $\begin{array}{l}\text { Eliminação } \\
\text { urinária alterada }\end{array}$ & $\begin{array}{l}\text { Distúrbio na eliminação urinária. Define-se por freqüência da eliminação urinária aumentada, } \\
\text { incontinência, nictúria, entre outros. Esse diagnóstico está relacionado a várias causas, entre elas: } \\
\text { sensibilidade motora prejudicada, infecção do trato urinário }{ }^{(38,39)} \text {. }\end{array}$ \\
\hline
\end{tabular}

A meta da prevenção das LTP é evitar seu desenvolvimento. Porém, acredita-se que a detecção da LTP ainda em estágio I e a adoção de medidas corretas de prevenção, podem apresentar resultados positivos, demonstrando que a assistência de enfermagem foi eficaz, pois neste estágio não há rompimento da pele, ou seja, é possível impedir maiores complicações decorrentes de LTP. Para tanto, o enfermeiro deve prestar a máxima atenção a sinais de hiperemia, flictena com hiperemia e formação de crosta nas áreas de sustentação de peso quando não há trauma.

No exame físico é possível avaliar se a lesão atingiu camadas mais internas da pele palpando o tecido próximo ao local de hiperemia, investigando áreas rijas com mudança de temperatura. No cliente com pele clara, deve ser observada qualquer coloração alterada, através da pressão com os dedos, esse exame permite verificar se a sua coloração volta ao normal quando a pressão é retirada ${ }^{(31)}$. Caso permaneça o sinal avermelhado é indicativo de lesão.

\section{Plano de Cuidados}

Durante o plano de cuidados, o enfermeiro elabora as ações de enfermagem visando resolver os problemas encontrados durante a fase de diagnósticos. Os cuidados devem ser reavaliados periodicamente com o objetivo de aprimoramento do planejamento das ações.
Utilizado para tornar a assistência de enfermagem mais eficiente e eficaz, o plano de cuidados deve ser pensado de forma a considerar as individualidades de cada cliente, como doenças de base, estado nutricional, comprometimento neurológico e mobilidade prejudicada. Consideram-se também, os recursos humanos e tecnológicos disponíveis para implementação desta fase $\mathrm{e}^{(31,40)}$.

Deve ser inserido no plano de cuidados da assistência de enfermagem um método de avaliação de risco de exposição do cliente à LTP. Esta iniciativa deve ocorrer o mais precocemente possível, na admissão do cliente. Porém, mesmo sendo as escalas de avaliação uma ferramenta importante devem ser complementadas com o julgamento clínico do enfermeiro, pois se acredita ser a maneira mais eficaz de avaliação do risco de desenvolvimento da

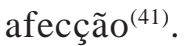

Atualmente, existem cerca de 40 escalas para avaliação de risco de LTP, porém a primeira escala desenvolvida foi a de Norton em $1962^{(41)}$. Podem ser citados exemplos mais recentes como as escalas de Braden e Waterlow.

A escala de Braden tem sua eficácia comprovada em estudos ${ }^{(42-43)}$ sendo mencionada por Potter e nas orientações da Agency for Health Care Policy and Research (AHCPR), entre outros. Nela são descritos seis fatores para a avaliação dos riscos 
de desenvolvimento de LTP: 1. Percepção sensorial avalia a capacidade de responder a compressão relacionada ao desconforto; 2 . Umidade - avalia o grau de umidade a que a pele está exposta; 3 . Atividade - avalia o grau de atividade física; 4. Mobilidade avalia a capacidade de alterar e controlar o posicionamento do corpo; 5. Nutrição - avalia o estado nutricional quanto à ingestão de proteína; 6. Fricção e cisalhamento - avalia o grau de contato entre a pele e o lençol de acordo com a mobilidade do indivíduo.

Esses fatores podem ser pontuados de 1 a 4 (com exceção do fator fricção e cisalhamento, que é pontuado de 1 a 3), em que o total somado varia de 6 a 23. Quanto menor o escore, mais chance de desenvolvimento de $\operatorname{LTP}^{(31,44)}$.

Outro método de avaliação que merece destaque é a escala de Waterlow, que tem como diferencial a avaliação da pele como fator de risco.
Esta escala foi desenvolvida a partir da escala de Norton, mas tem maior número de itens para avaliação $^{(41)}$.

Durante a utilização do método de avaliação escolhido, deve-se realizar exame físico, atentando para a situação geral da pele: se está muito seca, desidratada, se há áreas de hiperemia, edema, se há áreas potenciais de ruptura, observar regiões como áreas sob aparelhos gessados, tração, talas, colares, dentre outros $^{(31)}$. É importante ressaltar que os clientes em risco de desenvolvimento de LTP devem ser avaliados todos os dias, através da escala escolhida e do exame físico, em que deve ser prestada especial atenção aos locais de proeminência óssea ${ }^{(35)}$.

Além da avaliação do risco de desenvolvimento de LTP, complementa-se o plano de cuidados visando diminuir o risco de exposição do cliente executandose as ações contidas no quadro a seguir.

Quadro 2 - Plano de cuidados para a prevenção de LTP

$$
\text { Prescrição }
$$

1. Avaliar o cliente em risco de desenvolvimento de LTP diariamente. Dar especial atenção a proeminências ósseas $^{(31)}$.

\section{Posicionar corretamente o} cliente no leito ${ }^{(31)}$.

3. Manter a pele limpa, utilizando para tanto água e sabão, evitando força e fricção $\mathrm{O}^{(31,35)}$.

4. Reduzir agentes externos causadores de LTP: umidade, exposição ao frio $^{(31)}$.

5. Hidratar a pele, evitando massagear proeminências ósseas $^{(31)}$.

6. Diminuir o contato da pele com a umidade por incontinência urinária, fecal ou drenagem de ferida, fístula, estomas ou perspiração ${ }^{(31)}$.

7. Evitar cisalhamento e fricção provocados pela má-utilização do lençol e posicionamento do cliente ${ }^{(31)}$.

8. Atentar para ingestão nutricional adequada, acionando o serviço de nutrição quando necessário ${ }^{(31)}$.

\section{Justificativa}

A avaliação contínua possibilita a detecção precoce de sinais de desenvolvimento de LTP, permitindo que medidas sejam adotadas para interromper a progressão da injúria.

Documentar todas as alterações observadas na pele do cliente na avaliação tátil e visual. Havendo hiperemia, descrever o local, tamanho e coloração reavaliando a área após uma hora. Se a hiperemia é reativa, destaca-se a área com marcador para reavaliações posteriores.

Manter braços e cotovelos levemente afastados e flexionados. Posicionar o cliente com travesseiro sob o ombro e outro sobre a perna no mesmo lado, protegendo assim, o sacro e os trocânteres.

A fricção eleva o risco para LTP.

Mantida limpa, a pele fica menos exposta a traumas.

A troca de fraldas deve ser realizada sempre que necessário. Observar também a temperatura ambiente.

Aplicar emolientes à base de uréia ou ácido graxo essencial (AGE). Ao massagear proeminências ósseas, aumenta-se a pressão capilar.

A umidade reduz a resistência da pele à pressão proveniente da força de cisalhamento.

O cisalhamento provoca adesão das camadas da pele e tecido subcutâneo na superfície do leito. O trauma acontece nos tecidos subjacentes. Movimentar paciente sem arrastá-lo.

A desnutrição leva à perda de peso, atrofia muscular e massa tissular reduzida, diminuindo o tecido de acolchoamento entre pele e osso subjacente. A ingesta deficiente de proteínas e vitaminas retarda a cicatrização da ferida.

Continua 
9. Elaborar escala de mudança de decúbito com intervalos de $2 / 2 \mathrm{~h}$ ou de acordo com a necessidade ${ }^{(31)}$.

10. Proteger regiões trocantereana, sacra e calcânea ${ }^{(31)}$.

11. Manter cabeceira elevada até $30^{\circ}$ de acordo com as condições clínicas do doente ${ }^{(31)}$.

12. Diminuir tensão tecidual ${ }^{(31)}$.

13. Evitar o uso de almofadas em forma de anel para a região sacra ${ }^{(31)}$.
A detecção precoce da pressão indica a necessidade de mudanças de posição mais freqüentes.

Utilizar para este fim materiais como: filme transparente de poliuretano ou hidrocolóide extrafino. Com o peso do corpo sobre proeminências ósseas, a contraturas resultam em pressão exercida em locais inesperados.

Quando se eleva a cabeceira do leito acima de $30^{\circ}$, a pressão na região sacra aumenta consideravelmente. Cada caso deve ser avaliado

Manter o cliente em superfície que diminua a pressão sobre a pele, como: colchão caixa de ovo, colchão de ar estático, ar dinâmico, gel ou água.

Aumenta as chances de desenvolvimento de LTP nas áreas onde promove pressão.
Evolução de enfermagem: documentando os achados

Para Horta, a evolução de enfermagem é o relato diário ou periódico das mudanças sucessivas que ocorrem no cliente enquanto estiver sob assistência do enfermeiro, ou seja, uma avaliação global do plano de cuidados ${ }^{(46)}$. Nesse registro, devem constar os problemas novos identificados no quadro clínico do cliente, sob a forma de resumo sucinto dos resultados dos cuidados prescritos ${ }^{(47)}$. A evolução deve conter dados do registro relacionados ao diagnóstico e plano de cuidados que incluem, as alterações sensoriais bem como cada item prescrito de acordo com cada caso clínico.

O enfermeiro deve utilizar apurado raciocínio clínico para avaliar as etapas implementadas anteriormente para a prevenção das LTP. Para isso, deve investir em constante atualização e trabalho em equipe, tanto no que diz respeito à supervisão dos técnicos e auxiliares que implementam os cuidados prescritos, bem como na orientação destes profissionais envolvidos no cuidado.

A educação permanente e a reorientação da visão crítica dos profissionais para prevenção mostramse muito relevantes na atual conjuntura política de nosso sistema de saúde. Estudo mostra que a equipe de enfermagem ainda comete erros relacionados aos cuidados no tratamento de lesões teciduais e o papel do enfermeiro na prevenção da LTP é desconhecido ${ }^{(48)}$.

\section{CONCLUSÃO}

O desenvolvimento de LTP está intimamente ligado à qualidade da assistência de enfermagem prestada, embora esta não seja a única causa de LTP.
A sistematização da assistência de enfermagem é eficaz na prevenção de LTP, o que pôde ser comprovado através de pesquisas, é a forma de tornar essa assistência verdadeiramente eficaz, possibilitando ao cliente aquilo que é a essência da profissão: cuidar do outro quando este não é capaz de fazê-lo ou necessita de auxílio como supervisão/orientação.

A sistematização possibilita uma constante reflexão sobre a escolha das intervenções visando à prevenção de LTP, fazendo com que o enfermeiro desenvolva sua capacidade para tomar melhores decisões com crescente autonomia.

Os trabalhos analisados apresentaram aspectos relacionados à prevenção de forma parcial, na medida em que o foco dos estudos sobre LTP é o tratamento. A organização do cuidado curativista nos hospitais, em detrimento ao aspecto profilático, acaba por contribuir para essa realidade nas publicações.

É importante destacar que a prevenção é melhor alternativa, uma vez que evita a dor e sofrimento do cliente bem como reduz o tempo de internação e, conseqüentemente, os gastos relacionados com o tratamento, é nesta constatação que ganha espaço a aplicação do cuidado direcionado e individualizado de forma integral.

Enfim, para que a prevenção seja eficaz deve se desenvolver de forma sistematizada, tendo como base estudos previamente realizados. Ressalta-se a importância do enfermeiro estar constantemente atualizado sobre o assunto, pois é o profissional mais apropriado para lidar com o problema da LTP.

\section{REFERÊNCIAS}

1. Smeltzer SC, Bare BG. Princípios e práticas de 
reabilitação. In: Brunner e Suddarth, editores. Tratado de enfermagem médico-cirúrgica. $10^{a}$ ed. Rio de Janeiro: Guanabara Koogan; 2005. p.184-6.

2. Morison, M. J. Prevenção e tratamento de úlceras de pressão. Loures: Lusocência; 2004.

3. Allman RM, Goode PS, Burst N, Bartolucci AA, Thomas DR. Pressure ulcers, hospital complications, and disease severit: impact on hospital costs and lenght of stay. Adv wound care; 1999.

4. Rogenski NMB, Santos VLCG. Estudo sobre a incidência de úlceras por pressão em um hospital universitário. Rev Latino-Am Enferm. 2005;3(4):474-80.

5. Cardoso MCS; Caliri MHL; Hass VJ. Prevalência de úlceras de pressão em pacientes críticos internados em um hospital universitário. Rev Min Enferm. 2004;8(2):316-20.

6. Rabeh SAN. Úlcera de pressão: a clarificação do conceito e estratégias para divulgação do conhecimento na literatura de enfermagem [dissertação]. Ribeirão Preto (SP): Universidade de São Paulo; 2001.

7. National Pressure Ulcer Adivisory Panel (NPUAP). Pressure Ulcers: incindence, economics, risk assessment. Consensus development conference statement. Decubitus. 1989;2(2):24-8.

8. Declair V. Aplicação do triglicerídios de cadeia média (TCM) na prevenção de úlceras de decúbito. Rev Bras Enferm. 1994 Jan/Mar;47(1):27-30.

9. Fernandes LM. Úlcera por pressão em clientes críticos hospitalizados. Uma revisão integrativa da literatura [dissertação]. Ribeirão Preto (SP): Universidade de São Paulo; 2000.

10. Silva MSML. Fatores de risco para úlcera de pressão em pacientes hospitalizados João Pessoa [dissertação]. João Pessoa (PB): Universidade Federal da Paraíba;1998.

11. Agency for Health Care Policy and Research (AHCPR). Pressure ulcers in adults: prediction and prevention U.S. Clinical practice Guideline N.3. Departament of Health and Human Services; 1992. Publication n. 92-0047;

12. Jorge SA, Dantas SRPE. Abordagem multiprofissional do tratamento de feridas. São Paulo: Atheneu; 2005.

13. Silverthorn DU. Fisiologia humana: uma abordagem integrada. $2^{\mathrm{a}}$ ed. São Paulo: Manole; 2003.
14. Smeltzer SC, Bare BG. Histórico da função tegmentar. In: Brunner e Suddarth, editores. Tratado de enfermagem médico-cirúrgica. $10^{\mathrm{a}}$ ed. Rio de Janeiro: Guanabara Koogan; 2005. p.1733-8.

15. Blanes L, Duarte IS, Calil JA, Ferreira LM. Avaliação clínica e epidemiológica das úlceras por pressão em clientes internados no Hospital São Paulo. Rev Assoc Med Bras. 2004;50(2):182-7.

16. Hess CT. Tratamento de feridas e úlceras. $4^{\mathrm{a}}$ ed. Rio de Janeiro: Reichmann e Affonso; 2002.

17. Oroxo, SS. Avaliação de feridas: uma descrição para a sistematização da assistência. Enferm Brasil. 2006 Jan/ Fev;(5):1.

18. Barros SKSA; Anami EHT; Moraes MP. A elaboração de um protocolo para prevenção de úlcera por pressão por enfermeiros de um hospital de ensino. Nursing. 2003;63(6):29.

19. Kreutz I, Silva LM. Pele: grande, importante e tão esquecida pelo enfermeiro. Rev Pelle Sana. 1997;1(3):1.

20. Bergstrom N, Allman RM, Carlson CE, Eaglstein W, Frantz RA, Garber SL, et al. Pressure ulcers in adults: prediction and prevention clinical practice guideline. Number 3. Rockville: U.S. Department of health device, agency for halth care policy and research; May 1992.

21. Maia LCM, Monteiro MLG. Prevenção e tratamento de úlceras de pressão. In: Silva RCL, Figueiredo NMA, Meireles IB. Feridas fundamentos e atualizações em enfermagem. $1^{\text {a }}$ ed. São Caetano do Sul SP: Yendis; 2007. p.365-79.

22. Gogia PP. Feridas: tratamento e cicatrização. Rio de Janeiro: Revinter; 2003.

23. Poletti NAA. O cuidado de enfermagem a pacientes com feridas crônicas: a busca de evidências para a prática [dissertação]. Ribeirão Preto (SP): Escola de Enfermagem de Ribeirão Preto. Universidade de São Paulo; 2000.

24. Ministério da Saúde (BR). Secretaria Executiva Subsecretaria de Assuntos Administrativos. Vocabulário da saúde em qualidade e melhoria da gestão. Brasília: MS; 2002.

25. Rouquayrol MZ, Filho NA. Epidemiologia e saúde. $6^{\mathrm{a}}$ ed. Rio de Janeiro: Medsi 2003.

26. Figueiredo NMA, Machado WCA, Porto IS. O toque

Cogitare Enferm 2008 Out/Dez; 13(4):566-75 
no corpo e a prevenção de escaras. Rev Enferm UERJ. 1996; (n esp):71-80.

27. Figueiredo NMA, Machado WCA, Porto IS. O toque no corpo e a prevenção de escaras. Rev Enferm UERJ. 1996; (n esp):71-80.

28. Milani CS, Roteiro de sistematização de práticas de desenvolvimento local. Salvador: Universidade Federal da Bahia, Escola de Administração; 2005.

29. Thomaz VA, Guidardello EB. Sistematização da assistência de enfermagem: problemas identificados pelos enfermeiros. Nursing. 2002;5(54):28-34.

30. Sperandio, DJ. Sistematização da assistência de enfermagem: proposta de um software - protótipo [dissertação]. Ribeirão Preto (SP): Universidade de São Paulo; 2002.

31. Hermida PM; Araújo IE. Sistematização da assistência de enfermagem: subsídios para implantação. Rev Bras Enferm. 2006;59(5):675-9.

32. Poter PA, Perry AG. Fundamentos de enfermagem. $5^{\text {a }}$ ed. Rio de Janeiro: Guanabara Koogan; 2004.

33. Faro ACM. Fatores de risco para úlcera de pressão: subsídios para a prevenção. Rev Esc Enferm USP. 1999;33(3):279-83.

34. Dealey C. Cuidando de feridas, um guia para as enfermeiras. $2^{a}$ ed. São Paulo: Atheneu; 2001.

35. Ferreira LM. Etiopatogenia e tratamento das úlceras por pressão. Diagn Tratam. 2001;6(3):36-40.

36. Ito PE; Guariente MHDM; Barros SKSA; Anami EHT; Kassai F; Sá DM. Aplicação do protocolo de monitorização em paciente com risco de desenvolver úlcera de pressão: um estudo de caso. Arq Cienc Saúde UNIPAR. 2004;8(1):79-84.

37. Rangel EML. Conhecimento, práticas e fontes de informação de enfermeiros de um hospital sobre a prevenção e tratamento da úlcera de pressão [dissertação]. Ribeirão Preto (SP): Escola de Enfermagem de Ribeirão Preto; 2004.

38. Freitas EV, Py L, Cançado F, Doll J, Gorzoni M. Tratado de geriatria e gerontologia. $2^{\text {a }}$ ed. Rio de Janeiro: Guanabara Koogan; 2006.

39. Carpenito LJ. Diagnóstico de enfermagem aplicação à prática clínica. 8ªed. Porto Alegre: Artmed; 2002.
40. North American Nursing Diagnosis Association. Diagnóstico de enfermagem da Nanda - definições e classificações 2003-2004. Porto Alegre: Artmed; 2005.

41. Guimarães EMP, Spagnol CA, Ferreira E, Salviano ME. Utilização do plano de cuidados como estratégia de sistematização da assistência de enfermagem. Ciênc Enferm. 2002;8(2):49-58.

42. Rocha ABL, Barros SMO. Avaliação de risco de úlcera por pressão: propriedades de medida da versão em português da escala de Waterlow. Acta Paul Enferm. 2007;20(2):143-50.

43. Seongsook J, Ihnsook J, Younghee L. Validity of pressure ulcer risk assessment scales; Cubbin and Jackson, Braden, and Douglas scale. Int J Nurs Stud. 2004;41:199-204.

44. Blümel MEJ, Tirado GK, Schiele MC, Schonffeldt FG, Sarrá CS. Validez de la escala de Braden para predecir úlceras por presión en población femenina. Rev Med Chile. 2004;132(5):595-600.

45. Sousa CA, Santos I, Silva LD. Aplicando recomendações da escala de Braden e prevenindo úlceras por pressão - evidências do cuidar em enfermagem. Rev Bras Enferm. 2006 Mai;(59)3: 279-84.

46. Horta WA. Processo de enfermagem. In Foschiera F, Vieira CS. O diagnóstico de enfermagem no contexto das ações de enfermagem: percepção dos enfermeiros docentes e assistenciais. Rev Eletron Enferm [periódico on line] 2004 [acesso 2007 Jun 22]6(2). Disponível em: http://www.fen.ufg.br/revista/revista6_2/diag.html.

47. Brasil. Resolução no 272 de 27 de agosto de 2002 do Conselho Federal de Enfermagem. Dispõe sobre a sistematização da assistência de enfermagem - SAE nas Instituições de Saúde Brasileiras. [periódico on line]. [acesso 20 agosto 2007]. Disponível em: URL: http:/ /www.corensp.org.br/resolucoes/resolucoes.html.

48. Martins DA, Soares FFR. Conhecimento sobre prevenção e tratamento de úlceras de pressão entre trabalhadores de enfermagem em um hospital de Minas Gerais. Cogitare Enferm. 2008 Jan/Mar;13(1):83-7. 